\title{
What is the best way to deliver subcutaneous insulin to infants, children, and young people with type 1 diabetes mellitus?
}

\author{
J C Blair consultant endocrinologist ${ }^{1}$, M Peak director of research ${ }^{2}$, J W Gregory professor in \\ paediatric endocrinology ${ }^{3}$ \\ ${ }^{1}$ Department of Endocrinology, Alder Hey Children's NHS Foundation Trust, Eaton Road, Liverpool L12 2AP, UK; ${ }^{2}$ Department of Research and \\ Development, Alder Hey Children's NHS Foundation Trust ; ${ }^{3}$ Department of Child Health, School of Medicine, Cardiff University, Cardiff, UK
}

\begin{abstract}
This is one of a series of occasional articles that highlight areas of practice where management lacks convincing supporting evidence. The series adviser is David Tovey, editor in chief, the Cochrane Library. This paper is based on a research priority identified and commissioned by the National Institute for Health Research's Health Technology Assessment programme on an important clinical uncertainty. To suggest a topic for this series, please email us at uncertainties@bmj.com.
\end{abstract}

Type 1 diabetes is a common disease of childhood affecting approximately 23000 children and young people in England. ${ }^{1}$ The daily management of type 1 diabetes is burdensome. However, over a lifetime, long term complications are likely to have the greatest adverse impact on quality of life, and pose a significant economic burden to society and the NHS. The prevalence of long term complications is lowest in those with good glycaemic control using intensive insulin regimes in the form of insulin pump therapy or multiple daily injections. ${ }^{2} \mathrm{~A}$ recent review of paediatric diabetes services in the United Kingdom reported that $94 \%$ of centres offered intensive insulin regimes, and $78 \%$ offer treatment with insulin pump therapy. ${ }^{3}$ Despite the widespread availability of insulin pump therapy, data published by the National Diabetes Information Service in 2010 reported that only 1812 people aged less than 18 years were treated with insulin pumps in England. ${ }^{4}$

The National Institute for Health and Clinical Excellence recommends insulin pump therapy as a treatment option from diagnosis of type 1 diabetes for patients aged less than 12 years and for those aged 12 years and above with inadequate glycaemic control on multiple daily injections or disabling hypoglycaemia, ${ }^{5}$ with the intention of optimising glycaemic control and quality of life. However, the authors of this guideline recognise that the evidence supporting their recommendations is poor. The additional cost of insulin pump therapy is estimated to be $£ 1700$ ( $€ 1950 ; \$ 2770$ ) per annum. ${ }^{6}$ At present there is little robust evidence that this additional investment significantly improves glycaemic control, reduces the prevalence of long term complications, or improves quality of life in the paediatric population. We consider the strengths and weaknesses of the key evidence informing national guidelines and clinical practice.

\section{What is the evidence of the uncertainty?}

We searched the Cochrane Library, the Health Technology Assessment library, and MEDLINE, using the terms and MeSH headings: diabetes, continuous subcutaneous injection, insulin pump, multiple daily injections, MDI, child, infant, adolescent. A large number of studies were found. These have been critically appraised in two meta-analyse ${ }^{78}$ and a Health Technology Assessment ${ }^{6}$ review.

A Cochrane review ${ }^{7}$ reported data from seven paediatric randomised controlled trials collectively studying 210 individuals. ${ }^{9-15}$ Studies are summarised in the table $\Downarrow$. Observation periods ranged from six days to two years. It was estimated that in those treated with insulin pump therapy, $\mathrm{HbA}_{1 \mathrm{c}}$ was 0.2 percentage points lower (95\% confidence interval $0.40 \%$ to $0.03 \%(\mathrm{p}=0.02)$ ) compared with those treated with multiple daily injections. Differences in study methodology precluded a meta-analysis of hypoglycaemic events.

A recent meta-analysis ${ }^{8}$ reported data from six paediatric randomised controlled trials ${ }^{10}{ }^{14-18}$ collectively studying 165 people observed for 4 to 12 months (table $\Downarrow$ ). The authors also reported a favourable effect of insulin pump therapy on $\mathrm{HbA}_{1 \mathrm{c}}$ of 0.2 percentage points $(95 \%$ confidence interval $0.40 \%$ to $0.10 \%(\mathrm{P}<0.001))$. Insulin dose was significantly lower in patients treated with insulin pump therapy $(0.22$ units $/ \mathrm{kg} / \mathrm{day}$, 95\% confidence interval 0.31 to $0.14(\mathrm{P}<0.001))$. There was no statistically significant difference in the rate of severe hypoglycaemic events or diabetic ketoacidosis. 
A meta-analysis of quality of life was not undertaken in either study because of methodological differences between randomised controlled trials. Three studies ${ }^{913}{ }^{17}$ used the Diabetes Treatment Satisfaction Questionnaire and all reported greater satisfaction in those treated with insulin pump therapy. The Diabetes Quality of Life Questionnaire for the Young was used in three studies. ${ }^{910}{ }^{17}$ There was no difference in outcomes between treatment groups in two studies, ${ }^{10}{ }^{17}$ whereas one group reported greater satisfaction in patients treated with insulin pump therapy but no difference in measures of worry or impact. ${ }^{9}$

Although there is a trend for these meta-analyses to report a favourable effect of insulin pump therapy on glycaemic control, it is difficult to be certain of the importance of this modest reduction in $\mathrm{HbA}_{1 \mathrm{c}}$ on long term clinical outcomes, despite the fact that it is generally accepted that differences in $\mathrm{HbA}_{1 \mathrm{c}}$ of $0.5 \%$ or greater are clinically significant.

There are a number of methodological weaknesses in most studies reported to date. Studies recruiting patients with poor glycaemic control and randomising to continued multiple daily injections or a switch to insulin pump therapy may show an improvement with insulin pump therapy, for two reasons:

(1) Selection bias of participants with a preference for insulin pump therapy: patients on established multiple daily injections with good glycaemic control who are satisfied with their current therapy are less likely to be approached or agree to participate in these studies.

(2) Increased contact with diabetes healthcare professionals: at the start of insulin pump therapy patients receive an intensive period of education.

The observation periods in many studies are likely to be too brief for patients to acquire the skills required to use insulin pumps to their full potential, ${ }^{1011} 1417$ in others too brief to show patient fatigue in the use of this intensive therapy, ${ }^{9}{ }^{15}{ }^{16}$ and no study has been of sufficient duration to evaluate the impact of insulin pump therapy on long term complications. The number of patients recruited to each study is small, between 16 and 72 per study.

To date, there are only two multicentre studies, ${ }^{12}{ }^{13}$ one two-centre study, ${ }^{18}$ and three ${ }^{91417}$ of the ten randomised controlled trials are single-centre. Also, to date no randomised controlled study has been delivered in the UK, where healthcare services differ from those in which insulin pump therapy and multiple daily injections have previously been studied. No study has investigated the health economics of insulin pump therapy. Finally, most studies do not use "best possible multiple daily injections" as the comparator to insulin pump therapy. Insulin analogues have been reported to improve glycaemic control in paediatric practice ${ }^{19}$ though only one study uses analogue insulin for the treatment of all patients using multiple daily injections. ${ }^{10}$

The Health Technology Assessment review ${ }^{6}$ reported evidence from a wider range of sources, including seven randomised controlled trials $^{9} 0^{14-18}$ and 28 observational studies reporting data from 158 patients observed from 7 to 12 months and 1792 patients observed from six months to five years respectively. Representations from patients and industry were also included. The authors concluded that there was a modest reduction in $\mathrm{HbA}_{1 \mathrm{c}}$ in patients treated with insulin pump therapy, but a more important reduction in hypoglycaemic events. The authors reported that improvements in glycaemic control were greater in observational studies than in randomised controlled trials and recognised that these studies are more prone to bias. However, they also commented that observational studies may be more representative of clinical practice. The authors highlighted a number of benefits in quality of life including a reduction in the fear of hypoglycaemia, greater flexibility, and increased ability to cope with unexpected exercise and food.

\section{Is ongoing research likely to provide relevant evidence?}

We found only two studies in a search of the World Health Organization's International Clinical Trials Research Platform Portal (Australia New Zealand Trials Registry, clinicaltrials. gov, ISRCTN register) using the terms "children" AND "type 1 diabetes" AND ("pumps" OR “subcutaneous").

ACTRN12610000605099 will recruit 110 young people aged nine to 15.5 years with type 1 diabetes to investigate the effect of insulin pump therapy compared to multiple daily injections of insulin on parental report of behaviour four months after randomisation.

ISRCTN29255275 is led by the authors of this paper. The study will recruit 316 children and young people aged six months to 15 years with newly diagnosed type 1 diabetes to investigate the effect of insulin pump therapy compared to multiple daily injections on glycaemic control, as measured by $\mathrm{HbA}_{1 c}, 12$ months after diagnosis. Secondary outcomes include measures of quality of life and an economic analysis extrapolated to estimate lifetime costs and benefits.

\section{What should we do in the light of the uncertainty?}

To date there are insufficient data to recommend the use of insulin pump therapy rather than multiple daily injections as treatment of first choice to children with type 1 diabetes. Until more robust data are available, treatment with insulin pump therapy should be reserved for those in whom glycaemic control is inadequate, or for those with disabling hypoglycaemia. There is some evidence that quality of life and satisfaction may be improved during insulin pump therapy, but our ability to measure this in routine clinical practice is probably inadequate (although individual and family preference should not be overlooked). Finally, it is important to recognise that the long term benefits of insulin pump therapy are unproven and the benefits and costs of therapy to the individual should be critically appraised on a regular basis.

JCB developed the ideas for this paper with MP, and JWG searched and appraised the literature, drafted and revised the manuscript and gave final approval of the article. JCB is chief investigator of study ISRCTN29255275. MP has contributed to the development of this manuscript through searching and appraisal of literature and is a co-applicant on study ISRCTN29255275. He has also contributed to the drafting, editing, revision and approval of this article. JWG has contributed to the ideas behind this manuscript and is a co-applicant on study ISRCTN29255275. He has also contributed to the drafting, revision and approval of this article. JCB is guarantor.

Competing interests: All authors have completed the Unified Competing Interest form at www.icmje.org/coi_disclosure.pdf (available on request from the corresponding author) and declare: study ISRCTN29255275 is led by the authors of this paper. It is funded by the Health Technology Assessment programme of the National Institute for Health Research. The study team and Roche Diagnostics have agreed that where insulin pumps and consumables supplied by Roche Diagnostics are used the cost will be discounted by $25 \%$. JCB has received payment for consultancy work and speaker's fees from Novo Nordisk, and is a chief investigator for a study funded by Novo Nordisk. Novo Nordisk and Pfizer have sponsored a nurse salary within the Department of Endocrinology at Alder Hey Children's NHS Foundation Trust. JCB and 


\section{Recommendation for further research}

Population: infants aged more than 6 months, children, and young people

Intervention and comparison: insulin pump therapy compared with multiple daily injections

Outcome: glycaemic control, frequency of severe hypoglycaemia and diabetic ketoacidosis, quality of life, growth and weight gain, insulin requirements, and cost effectiveness based on the incremental cost per quality of adjusted life years (QALY) gained

JWG have received expenses for academic meetings from Novo Nordisk, Pfizer, and Ipsen. JWG is a member of an advisory board for Bayer, and has received speaker's fees from Bayer, an unrestricted research grant from Novo Nordisk, and payment for developing educational materials from Pfizer. JWG has been a member of the National Institute for Health Research Health Technology Assessment commissioning board in the past year, but was not involved in decisions around the funding of study ISRCTN29255275. They had no other relationships or activities that could appear to have influenced the submitted work.

Provenance and peer review: Commissioned; externally peer reviewed.

1 Royal College of Paediatrics and Child Health (2009). Growing up with diabetes: children and young people in England. www.rcpch.ac.uk/news/first-national-survey-finds-23000children-diabetes-england-06-april-2009.

2 The Diabetes Control and Complications Trial Research Group. The effect of intensive treatment of diabetes on the development and progression of long-term complications in insulin-dependent diabetes mellitus. N Engl J Med 1993;329:977-86.

3 Gosden C, Edge JA, Holt RI, James J, Turner B, Winocour P, et al. The fifth UK paediatric diabetes services survey: meeting guidelines and recommendations? Arch Dis Child 2010;95:837-40.

4 National Diabetes Information Service. Insulin Pump Audit-Findings for England. 2009 www.diabetes.nhs.uk/document.php?o=1706.

5 National Institute for Health and Clinical Excellence. Continuous subcutaneous insulin infusion for the treatment of diabetes mellitus (review of technology appraisal guidance 57). June 2011. NICE technology appraisal guidance 151 (2008). www.nice.org.uk/TA151.

6 Cummins E, Royle P, Snaith A, Greene A, Robertson L, McIntyre L, et al. Clinical effectiveness and cost-effectiveness of continuous subcutaneous insulin infusion for diabetes: systematic review and economic evaluation. Health Technology Assessment 2010;14(11).

7 Misso ML, Egberts KJ, Page M, O'Connor D, Shaw J. Continuous subcutaneous insulin infusion (CSII) versus multiple insulin injections for type 1 diabetes mellitus. Cochrane Database Syst Rev 2010;1:CD005103.

8 Pańkowska E, Błazik M, Dziechciarz P, Szypowska A, Szajewska H. Continuous subcutaneous insulin infusion vs. multiple daily injections in children with type 1 diabetes: a systematic review and meta-analysis of randomized control trials. Pediatr Diabetes 2009;10:52-8.
9 Cohen D, Weintrob N, Benzaquen H, Galatzer A, Fayman G, Phillip M. Continuous subcutaneous insulin infusion versus multiple daily injections in adolescents with type 1 diabetes mellitus: a randomized open crossover trial. J Pediatr Endocrinol Metab 2003;16:1047-50.

10 Doyle EA, Weinzimer SA, Steffen AT, Ahern JA, Vincent M, Tamborlane WV. A randomized, prospective trial comparing the efficacy of continuous subcutaneous insulin infusion with multiple daily injections using insulin glargine. Diabetes Care 2004;27:1554-8.

11 Meschi F, Beccaria L, Vanini R, Szulc M, Chiumello G. Short-term subcutaneous insulin infusion in diabetic children. Comparison with three daily insulin injections. Acta Diabetol Lat 1982;19:371-5.

12 Nuboer R, Borsboom GJ, Zoethout JA, Koot HM, Bruining J. Effects of insulin pump vs. injection treatment on quality of life and impact of disease in children with type 1 diabetes mellitus in a randomized, prospective comparison. Pediatr Diabetes 2008;9:291-6.

13 Skogsberg L, Fors H, Hanas R, Chaplin JE, Lindman E, Skogsberg J. Improved treatmen satisfaction but no difference in metabolic control when using continuous subcutaneous insulin infusion vs. multiple daily injections in children at onset of type 1 diabetes mellitus. Pediatr Diabetes 2008:9:472-9.

14 Weintrob N, Schechter A, Benzaquen H, Shalitin S, Lilos P, Galatzer A, et al. Glycemic patterns detected by continuous subcutaneous glucose sensing in children and adolescents with type 1 diabetes mellitus treated by multiple daily injections vs continuous subcutaneous insulin infusion. Arch Pediatr Adolesc Med 2004;158:677-84.

15 DiMeglio LA, Pottorff TM, Boyd SR, France L, Fineberg N, Eugster EA. A randomized, controlled study of insulin pump therapy in diabetic pre-schoolers. J Pediatr 2004:145:380-4.

16 Fox LA, Buckloh LM, Smith SD, Wysocki T, Mauras N. A randomized controlled trial of insulin pump therapy in young children with type 1 diabetes. Diabetes Care 2005;28:1277-81.

17 Weintrob N, Benzaquen H, Galatzer A, Shalitin S, Lazar L, Fayman G, et al. Comparison of continuous subcutaneous insulin infusion and multiple daily injection regimens in children with type 1 diabetes: a randomized open crossover trial. Pediatrics 2003:112:559-64.

18 Wilson DM, Buckingham BA, Kunselman EL, Sullivan MM, Paguntalan HU, Gitelman SE. A two-center randomized controlled feasibility trial of insulin pump therapy in young children with diabetes. Diabetes Care 2005;28:15-9.

19 Schober E, Schoenle E, Van Dyk J, Wernicke-Panten K; Pediatric Study Group of Insulin Glargine. Comparative trial between insulin glargine and NPH insulin in children and adolescents with type 1 diabetes mellitus. J Pediatr Endocrinol Metab 2002;15:369-76.

Accepted: 20 July 2011

Cite this as: BMJ 2011;343:d5221

(c) BMJ Publishing Group Ltd 2011 


\section{Table}

Table 1/ Clinical characteristics and between group analyses in patients treated with insulin pump therapy and multiple daily injections studied in randomised controlled trials. Values are mean (standard deviation) unless stated otherwise

\begin{tabular}{|c|c|c|c|c|c|c|}
\hline \multirow[b]{2}{*}{ Study design } & \multirow{2}{*}{$\begin{array}{l}\text { Observation } \\
\text { period }\end{array}$} & \multicolumn{4}{|c|}{ Baseline characteristics of patients } & \multirow{2}{*}{$\begin{array}{l}\text { Difference in outcomes IPT } v \text { MDI at } \\
\text { study completion }\end{array}$} \\
\hline & & $\mathbf{N}$ & Age (years) & $\mathrm{HbA}_{1 \mathrm{c}}(\%)$ & Duration TID (years) & \\
\hline \multirow[t]{2}{*}{ Crossover $\mathrm{RCT}^{9}$} & \multirow{2}{*}{$\begin{array}{l}6 \text { months each } \\
\text { arm }\end{array}$} & \multirow[t]{2}{*}{16} & \multirow{2}{*}{$\begin{array}{l}\text { Median } 14.2 \text { (range } \\
\quad 14.1-17.5)\end{array}$} & IPT $8.6(0.8)$ & \multirow[t]{2}{*}{ Not reported } & \multirow{2}{*}{$\begin{array}{l}\text { No difference in } \mathrm{HbA}_{1 \mathrm{c}} \text { or severe } \\
\text { hypoglycaemia. Treatment satisfaction } 32.0 \\
\text { (6.5) } v 21.8(3.7), \mathrm{P}<0.05\end{array}$} \\
\hline & & & & MDI $8.5(1.4)$ & & \\
\hline \multirow[t]{2}{*}{ Parallel $\mathrm{RCT}^{10}$} & \multirow[t]{2}{*}{16 weeks } & \multirow[t]{2}{*}{32} & IPT 12.5 (3.2) & IPT $8.2(1.1)$ & IPT $6.8(3.8)$ & \multirow{2}{*}{$\begin{array}{l}\mathrm{HbA}_{1 \mathrm{c}}(\%): 7.2 v 8.1, \mathrm{P}<0.05 \text {. Insulin doses } \\
\text { (units/kg/day): } 0.9 \vee 1.2, \mathrm{P}<0.003 \text {. No } \\
\text { difference in quality of life }\end{array}$} \\
\hline & & & MDI $13.0(2.9)$ & MDI 8.1 (1.2) & MDI $5.6(4.0)$ & \\
\hline \multirow[t]{2}{*}{ Parallel $\mathrm{RCT}^{11}$} & \multirow[t]{2}{*}{6 days } & \multirow[t]{2}{*}{16} & IPT $13.3(4.0)$ & IPT $10.5(2.9)$ & \multirow[t]{2}{*}{ Not reported } & \multirow{2}{*}{$\begin{array}{l}\text { No significant difference in blood glucose } \\
\text { (mean of seven samples/day) or } 24 \text { hour } \\
\text { glycosuria }\end{array}$} \\
\hline & & & MDI $12.9(2.4)$ & MDI $10.7(1.1)$ & & \\
\hline \multirow[t]{2}{*}{ Parallel $\mathrm{RCT}^{12}$} & \multirow{2}{*}{$\begin{array}{l}\text { IPT } 10.5 \text { months; } \\
\text { MDI } 3.5 \text { months; } \\
\text { then IPT } 7 \\
\text { months }\end{array}$} & \multirow[t]{2}{*}{38} & IPT $10.0(3.0)$ & IPT $8.3(0.8)$ & IPT $5.6(3.3)$ & \multirow{2}{*}{$\begin{array}{l}\text { No significant difference in quality of life or } \\
\text { glycaemic control }\end{array}$} \\
\hline & & & MDI $10.0(3.7)$ & MDI $8.4(1.1)$ & MDI 4.7 (2.9) & \\
\hline \multirow[t]{2}{*}{ Parallel $\mathrm{RCT}^{13}$} & \multirow[t]{2}{*}{2 years } & \multirow[t]{2}{*}{72} & IPT $11.8(4.9)$ & IPT $8.2(0.4)$ & IPT $12.2(2.0)$ & \multirow{2}{*}{$\begin{array}{l}\text { No difference in } \mathrm{HbA}_{1 \mathrm{c}} \text { or severe } \\
\text { hypoglycaemia. Insulin doses (units/kg/day): } \\
0.7 \text { v } 1.1, \mathrm{P}=0.001 \text {. Treatment satisfaction: } \\
33.1 \text { (0.9) v } 27.5(2.0), \mathrm{P}<0.001\end{array}$} \\
\hline & & & MDI $12.3(4.5)$ & MDI $8.4(0.5)$ & MDI 10.4 (1.7) (days) & \\
\hline Crossover $\mathrm{RCT}^{14}$ & $\begin{array}{l}3.5 \text { months each } \\
\text { arm }\end{array}$ & 23 & $\begin{array}{c}\text { Median } 11.9 \text { (9.3 to } \\
13.3)\end{array}$ & $\begin{array}{c}\text { Median } 8.9(6.1 \text { to } \\
10.1)\end{array}$ & $\begin{array}{c}\text { Median } 6.0(2.5 \text { to } \\
11.0)\end{array}$ & $\begin{array}{l}\text { No significant difference in } \mathrm{HbA}_{10} \text {, severe } \\
\text { hypoglycaemia, DKA, or quality of life. } \\
\text { Treatment satisfaction: } 30.6(3.7) v 21.9 \\
(3.8), \mathrm{P}<0.001\end{array}$ \\
\hline \multirow[t]{2}{*}{ Parallel $\mathrm{RCT}^{15}$} & \multirow[t]{2}{*}{6 months } & \multirow[t]{2}{*}{42} & IPT $3.8(0.8)$ & IPT $9.0(0.6)$ & IPT $1.8(0.6)$ & \multirow{2}{*}{$\begin{array}{l}\text { No difference in } \mathrm{HbA}_{1 \mathrm{c}} \text { or severe } \\
\text { hypoglycaemia }\end{array}$} \\
\hline & & & MDI $3.7(0.7)$ & MDI $9.0(0.6)$ & MDI $1.8(0.6)$ & \\
\hline \multirow[t]{2}{*}{ Parallel $\mathrm{RCT}^{16}$} & \multirow[t]{2}{*}{24 weeks } & \multirow[t]{2}{*}{26} & IPT $3.9(0.4)$ & IPT $7.4(0.5)$ & IPT $1.2(0.3)$ & \multirow{2}{*}{$\begin{array}{l}\text { No difference in } \mathrm{HbA}_{1 \mathrm{c}} \text { or severe } \\
\text { hypoglycaemia. Fathers of subjects reported } \\
\text { greater improvement in quality of life with } \\
\text { IPT } v \mathrm{MDI}, \mathrm{P}=0.03\end{array}$} \\
\hline & & & MDI $3.8(0.4)$ & MDI $7.6(0.3)$ & MDI $1.6(0.3)$ & \\
\hline Crossover $\mathrm{RCT}^{17}$ & 3.5 months each & 23 & Arm A 11.9 (1.4) & Arm A 8.0 (1.1) & Arm A 5.3 (1.9) & No difference in $\mathrm{HbA}_{10}$, number of \\
\hline & & & Arm B 11.9 (1.5) & Arm B $8.3(0.7)$ & Arm B 6.3 (2.6) & $\begin{array}{l}\text { hypoglycaemic events. Fasting glucose } \\
\text { within target (\%): } 27 \text { (20) v17 (16), P=0.01. }\end{array}$ \\
\hline & & & & & & $\begin{array}{l}\mathrm{AUC}(\mathrm{mg} / \mathrm{dL}), 24 \mathrm{hr}: 377 \text { (377) v } 638 \text { (727), } \\
\mathrm{P}=0.04 \text {. }\end{array}$ \\
\hline & & & & & & $\begin{array}{l}\text { Hyperglycaemic events, } 24 \text { hour: } 3.4(1.2) v \\
2.9(1.0), P=0.04\end{array}$ \\
\hline Parallel $\mathrm{RCT}^{18}$ & 52 weeks & 22 & $3.6(1.0)$ & $8.0(0.8)$ & $1.4(0.6)$ & $\begin{array}{l}\text { No difference in } \mathrm{HbA}_{10} \text {, quality of life, } \\
\text { episodes of severe hypoglycaemia or DKA }\end{array}$ \\
\hline
\end{tabular}

TID: type 1 diabetes; RCT: randomised controlled trial; IPT: insulin pump therapy; MDI: multiple daily injections; DKA: diabetic ketoacidosis; CGM: continuous glucose monitoring; AUC: area under the curve. 